\title{
Laparoscopic vs. Robotic Approach to Partial Colon Resection
}

\author{
Jordan L. White' ${ }^{1}$ Francis A. Buzad ${ }^{2}$, Herschel B. Patel ${ }^{1}$ \\ ${ }^{1}$ College Station, Texas A\&M Health Science Center, College of Medicine, Bryan, USA \\ ${ }^{2}$ General Surgery Department, North Austin Medical Center, Austin, USA \\ Email: jordanleighwhite@gmail.com
}

How to cite this paper: White, J.L., Buzad, F.A. and Patel, H.B. (2017) Laparoscopic vs. Robotic Approach to Partial Colon Resection. Surgical Science, 8, 348-357. https://doi.org/10.4236/ss.2017.88038

Received: July 20, 2017

Accepted: August 13, 2017

Published: August 16, 2017

Copyright $\odot 2017$ by authors and Scientific Research Publishing Inc. This work is licensed under the Creative Commons Attribution International License (CC BY 4.0).

http://creativecommons.org/licenses/by/4.0/ (c) (i) Open Access

\begin{abstract}
We retrospectively collected data on 130 minimally invasive colon resection cases performed by the same surgeon from April 2005 to February 2017, of which 35 were completed laparoscopically and 95 were completed robotically. The first 30 robotic cases were allocated to a Training group to account for the learning needed to stabilize operative ability. The 35 laparoscopic cases and 65 of the 95 robotic cases, starting with the $31^{\text {st }}$ case, were compared. Robotic partial colon resection was significantly more capable than the laparoscopic approach in limiting blood loss $(\mathrm{p}<0.05)$ during the procedure, lessening conversion to a traditional open approach $(\mathrm{p}<0.05)$, and produced a quantitatively larger lymph node harvest $(p<0.05)$. Patients of robotic cases also had overall shorter hospital stay $(\mathrm{p}<0.05)$. Laparoscopic cases were significantly shorter in terms of operation time $(\mathrm{p}<0.05)$. Laparoscopic and robotic approaches had similar rates of several aspects of morbidity and mortality. The robotic approach to partial colon resection is a technically capable modality of operation intraoperatively, as shown by increased lymph node harvest and less blood loss, and may provide some benefits to patients postoperatively, evidenced by shorter hospital stays, and potentially an oncologic benefit by obtaining higher lymph node harvest in cancer cases. Another benefit of the implementation of a robotic approach is the increased number of patients that are eligible for and ultimately undergo a safe and successful minimally invasive surgery as compared to a more traditional surgical approach.
\end{abstract}

\section{Keywords}

Robot, Da Vinci, Laparoscopic, Hemicolectomy, Colon Resection, Short-Term Outcomes

\section{Introduction}

There is a growing body of evidence that minimally invasive surgical techniques 
are superior to open approach in patient outcomes and overall cost [1] [2]. The advantages minimally invasive techniques are commonly accepted and widely demonstrated [3]. Our goal was to compare minimally invasive approaches towards colorectal resection, specifically laparoscopic and robotic-assisted surgery. Robotic-assisted surgery may be a safe and effective alternative to laparoscopic surgery, as it combines the advantages of minimally invasive surgery while allowing the technique and clarity of an open procedure [3] [4]. The use of robotics in surgery has incorporated a level of sophistication in the way of stabilization, 3-D visualization, and ergonomic support [3] [5] [6] [7].

The minimally invasive approach to surgery is widely applied to many digestive procedures in current surgery practice, including colon resection. However, there is still debate over whether robotic-assisted laparoscopy confers benefits over the more routinely used laparoscopic approach [7] [8] [9].

The objective of this study was to evaluate differences in laparoscopic and robotic-assisted surgery by evaluating short-term outcomes including hospital stay, morbidity, and mortality when used for partial colon resection. We also evaluated aspects of the operation including operation time, blood loss, and operation time. We hypothesized that robotic surgery would show benefits in terms of intraoperative ability and short-term patient outcomes due to the technical precision it offers intraoperatively.

\section{Materials and Methods}

\subsection{Study Design}

This study was an observational, retrospective single provider analysis of laparoscopic and robotic colon resections completed between April 2005 and February 2017 performed by one general surgeon at North Austin Medical Center (Austin, Texas). This surgeon gained prior laparoscopic experience during residency and subsequently in private clinical practice focused on minimally invasive surgery since 2001 .

The robot surgical system (da Vinci) was first introduced to this practice in 2008 and the first operation in which the system was used by this provider was in July 2008.

The inclusion criteria for cases included that the case was a non-emergent partial colon resection performed at North Austin Medical Center, and the attending surgeon directing the case was Dr. Francis Buzad. We did not exclude patients based on age, prior abdominal surgery, or anticipated outpatient treatment.

The variables that were analyzed in this study were collected by retrospective medical chart review. Two medical students collected data on operating time, estimated blood loss (EBL), post-op hospital stay, morbidity and mortality.

The sample was divided into three groups, of which two groups were analyzed. The first group was composed of all cases in which there was a laparoscopic approach and is therefore named Laparoscopic. Data was collected from 
cases performed between April 2005 and March 2011.

The second group was composed of the first 30 cases in which the surgeon attempted a robotic approach and is therefore named Training. There is evidence to suggest that robotic skills will stabilize after a substantial allowance for adaptation through an ample learning curve [10] [11]. The Training group was created to minimize variability in robotic-assisted surgery data that would be eliminated through experience with the technique.

The third group was composed of all colon resections with a robotic approach including the $31^{\text {st }}$ procedure and all robotic-assisted cases performed thereafter. This group was referred to as Robotic throughout this paper. Data was collected from cases performed between March 2009 and February 2017. Measures of efficacy included morbidity and mortality, blood loss, conversion to open, and length of hospital stay. Secondary outcomes included lymph node collection for oncologic cases.

Postoperative morbidity parameters were divided into local and systemic morbidity. Local morbidity included local hematoma formation, wound infection, anastomotic leak, intraperitoneal abscess, bowel obstruction, intraperitoneal bleeding, anastomotic stenosis, and significant anastomotic bleeding. Systemic morbidity included atelectasis producing fever, anemia requiring transfusion, prolonged ileus defined as return of bowel function delayed more than 3 days, urinary retention requiring catheterization, pneumonia, pulmonary embolism, pulmonary edema, cardiac arrest, and admittance to ICU care. Mortality in the perioperative period and reoperation rate was also evaluated.

There were 13 cases within the Laparoscopic group, 8 in the Training group, and 34 in the Robotic group that were pathologically evaluated for oncologic staging. The number of lymph nodes harvest in these cases was quantified for comparison between the Laparoscopic and Robotic groups.

\subsection{Statistical Analysis}

Discrete variables including operating time, blood loss, and hospital stay were expressed as the mean (standard deviation) and compared using the Mann Whitney U Test. Categorical variables including conversion to open surgery and post-op morbidity variables were expressed as frequency (percent) and compared using the Fisher Exact Test $\left(\mathrm{v}^{2}\right)$. Differences were considered significant if $p$ values were $<0.05$.

\section{Results}

Between April 2005 and February 2017, 130 partial colon resections were performed that fit the inclusion criteria for this study. Of these cases, 35 were Laparoscopic, 30 were in the Training group, and 65 were Robotic. Data from the Training group were excluded in statistical analysis, but are still applicable in the evaluation of patient characteristics and morbidity. Patient Characteristics are given in Table 1 . There was no statistically significant difference in age, sex, 
Table 1. Patient Characteristics.

\begin{tabular}{ccccc}
\hline & \multicolumn{3}{c}{ Group } & \multirow{2}{*}{$p^{*}$} \\
\cline { 2 - 4 } Patient Characteristics & $\begin{array}{c}\text { Laparoscopic } \\
(\mathrm{n}=35)\end{array}$ & $\begin{array}{c}\text { Training } \\
(\mathrm{n}=30)\end{array}$ & $\begin{array}{c}\text { Robotic } \\
(\mathrm{n}=65)\end{array}$ & 0.18 \\
\hline Age (years) & $66.8(14.4)$ & $56.8(11.9)$ & $63.1(14.2)$ & 0.83 \\
Sex (\%) & $18(51.4)$ & $10(33.5)$ & $36(55.4)$ & \\
Male & $17(48.6)$ & $20(66.7)$ & $29(44.6)$ & 0.67 \\
Female & $27.6(6.2)$ & $27.4(6.0)$ & $28.0(7.4)$ & \\
BMI (kg/m $\left.{ }^{2}\right)$ & $15(40.0)$ & $19(63.3)$ & $40(60.6)$ & \\
Previous Abdominal Surgery & & $19(63.3)$ & $36(54.5)$ & \\
Primary Operation & $10(28.6)$ & $27(40.9)$ & \\
Left Colectomy & $23(65.7)$ & $11(36.7)$ & $3(45.5)$ & \\
Right Colectomy & $2(5.7)$ & $0(0.0)$ & $25(37.9)$ & \\
Transverse Colectomy & & & $40(60.6)$ & \\
Diagnosis & $6(17.1)$ & $16(53.3)$ & $1.5)$ & \\
Diverticulitis & $27(77.1)$ & $14(46.7)$ & & \\
Colon Mass & $2(5.7)$ & $0(0.0)$ & \\
Other & & & & \\
\hline
\end{tabular}

Discrete data are given as mean values with standard deviation in parenthesis. Categorical data are given as raw values with percentage of total in parenthesis. ${ }^{*} p$ values of discrete data were calculated using Mann-Whitney U-Test to compare Laparoscopic and Robotic data, and categorical data was calculated using Fisher Exact Test to comparison of Laparoscopic and Robotic data.

Table 2. Intraoperative and Perioperative Outcomes.

\begin{tabular}{ccccc}
\hline \multirow{2}{*}{$\begin{array}{c}\text { Intraoperative and Perioperative } \\
\text { Outcomes }\end{array}$} & $\begin{array}{c}\text { Laparoscopic } \\
(\mathrm{n}=35)\end{array}$ & $\begin{array}{c}\text { Training } \\
(\mathrm{n}=30)\end{array}$ & $\begin{array}{c}\text { Robotic } \\
(\mathrm{n}=65)\end{array}$ & \multirow{2}{*}{$p^{*}$} \\
\cline { 2 - 4 } & $131.8(55.6)$ & $214.5(41.6)$ & $200.8(46.7)$ & $<0.01$ \\
Mean Operating Time (min) & $5.6(3.1)$ & $5.0(3.7)$ & $4.3(2.4)$ & 0.02 \\
Post-Op Hospital Stay (days) & $70.0(51.5)$ & $73.4(71.3)$ & $44.8(53.9)$ & $<0.01$ \\
\hline
\end{tabular}

Discrete data are given as mean values with standard deviation in parenthesis. Data for cases that were converted to open were excluded for comparison of discrete variables. ${ }^{*} p$ values of discrete data were calculated using Mann-Whitney U-Test to compare Laparoscopic and Robotic data.

BMI, or proportion of patients with previous abdominal surgery between the Laparoscopic and Robotic groups.

Intraoperative and Perioperative Outcomes are given in Table 2 and Figure 1. The time spent in the operating room was significantly longer in the Robotic group when compared to the Laparoscopic group, $(\mathrm{p}<0.05)$. The EBL was significantly less in the Robotic group when compared to the Laparoscopic group, $(\mathrm{p}<0.05)$. The postoperative hospital stay was significantly less in the Robotic group when compared to the Laparoscopic group, $(\mathrm{p}<0.05)$. 


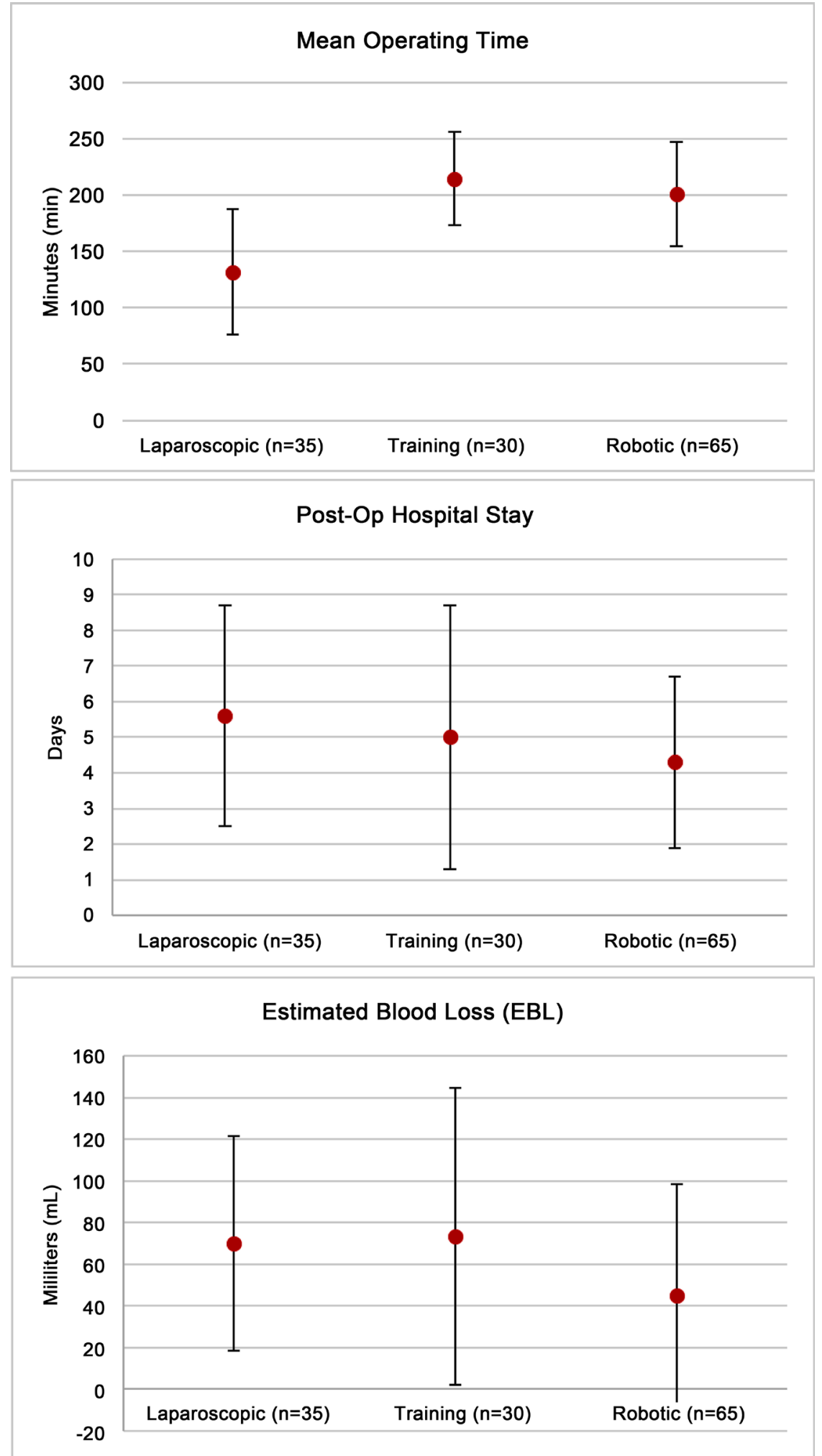

Figure 1. Intraoperative and Perioperative Outcomes: Mean Operating Time, Post-Op Hospital Stay, and EBL.

Post-operative morbidity and mortality rates are given in Table 3. In the Laparoscopic group, 12 cases were converted to open while only 3 were converted 
to open in the Robotic group ( $\mathrm{p}<0.05)$. There was no significant difference in rate of post-op morbidity between Laparoscopic and Robotic groups. The highest frequency of complication overall was prolonged ileus, followed by anastomotic bleeding. There were nine overall cases of ileus, four in the Laparoscopic, one in the Training, and three in the Robotic group. There were total four cases complicated by bleeding from the anastomotic closure, one in the Laparoscopic group requiring observation, one in the Training group requiring reoperation, and two in the robotic group. The two robotic cases were evidenced by a significant drop in hematocrit requiring one and two units of transfused blood. Bleeding resolved spontaneously in both cases without the need for reoperation.

Table 3. Morbidity and Mortality.

\begin{tabular}{|c|c|c|c|c|}
\hline \multirow[b]{2}{*}{ Morbidity and Mortality } & \multicolumn{3}{|c|}{ Group } & \multirow[b]{2}{*}{$p^{*}$} \\
\hline & $\begin{array}{l}\text { Laparoscopic } \\
\quad(\mathrm{n}=35)\end{array}$ & $\begin{array}{l}\text { Training } \\
(\mathrm{n}=30)\end{array}$ & $\begin{array}{l}\text { Robotic } \\
(\mathrm{n}=65)\end{array}$ & \\
\hline \multicolumn{5}{|l|}{ Intra-Operative Complication } \\
\hline Open Conversion & $12(34.2)$ & $4(20.0)$ & $3(4.6)$ & $<0.01$ \\
\hline Postoperative Morbidity & $7(20.0)$ & $8(40.0)$ & $16(24.2)$ & 0.80 \\
\hline \multicolumn{5}{|l|}{ Local } \\
\hline Hematoma & $1(2.9)$ & - & - & 0.35 \\
\hline Wound Infection & - & - & - & 1 \\
\hline Anastomotic Leak & - & $2(6.7)$ & - & 1 \\
\hline Intraperitoneal Abscess & - & - & - & 1 \\
\hline Bowel Obstruction & - & $1(3.3)$ & $2(3.1)$ & 0.54 \\
\hline Intraperitoneal Bleeding & - & - & - & 1 \\
\hline Anastomotic Stenosis & - & - & - & 1 \\
\hline Anastomotic Bleeding & $1(2.9)$ & $1(3.3)$ & $2(3.1)$ & 1 \\
\hline \multicolumn{5}{|l|}{ Systemic } \\
\hline Atelectasis & - & - & $1(1.5)$ & 1 \\
\hline Anemia Requiring Transfusion & - & - & $2(3.1)$ & 1 \\
\hline Ileus & $4(11.4)$ & $2(6.7)$ & $3(4.6)$ & 0.24 \\
\hline Urinary Retention & - & - & - & 1 \\
\hline Pneumonia & - & - & $1(1.5)$ & 1 \\
\hline Pulmonary Embolism & - & - & - & 1 \\
\hline Pulmonary Edema & - & - & $1(1.5)$ & 1 \\
\hline Cardiac Arrest & - & - & $1(1.5)$ & 1 \\
\hline ICU Care & $1(2.9)$ & - & $1(1.5)$ & 1 \\
\hline Mortality & - & - & $1(1.5)$ & 1 \\
\hline Reoperation & - & $2(6.7)$ & $1(1.5)$ & 1 \\
\hline
\end{tabular}

Data are given as raw numbers of patients are listed with percentage of total patients in parenthesis. ${ }^{*} p$ values were calculated using Fisher Exact Test for comparison of Laparoscopic and Robotic data. 
Table 4. Technical Ability.

\begin{tabular}{lcccc}
\hline \multirow{2}{*}{ Technical Ability } & \multicolumn{3}{c}{ Group } & \multirow{2}{*}{$p^{*}$} \\
\cline { 2 - 4 } & Laparoscopic $(\mathrm{n}=13)$ & Training $(\mathrm{n}=8)$ & Robotic $(\mathrm{n}=34)$ & \\
\hline Lymph Node Harvest & $12.4(3.9)$ & $15.9(3.1)$ & $23.6(8.6)$ & $<0.01$ \\
\hline $\begin{array}{l}\text { Data includes cases where resection was indicated for a colon mass and subsequent pathologic evaluation } \\
\text { required oncologic staging. Cases in which conversion to open were required were excluded. * } p \text { values were } \\
\text { calculated using Mann-Whitney U-Test to compare Laparoscopic and Robotic groups. }\end{array}$ &
\end{tabular}

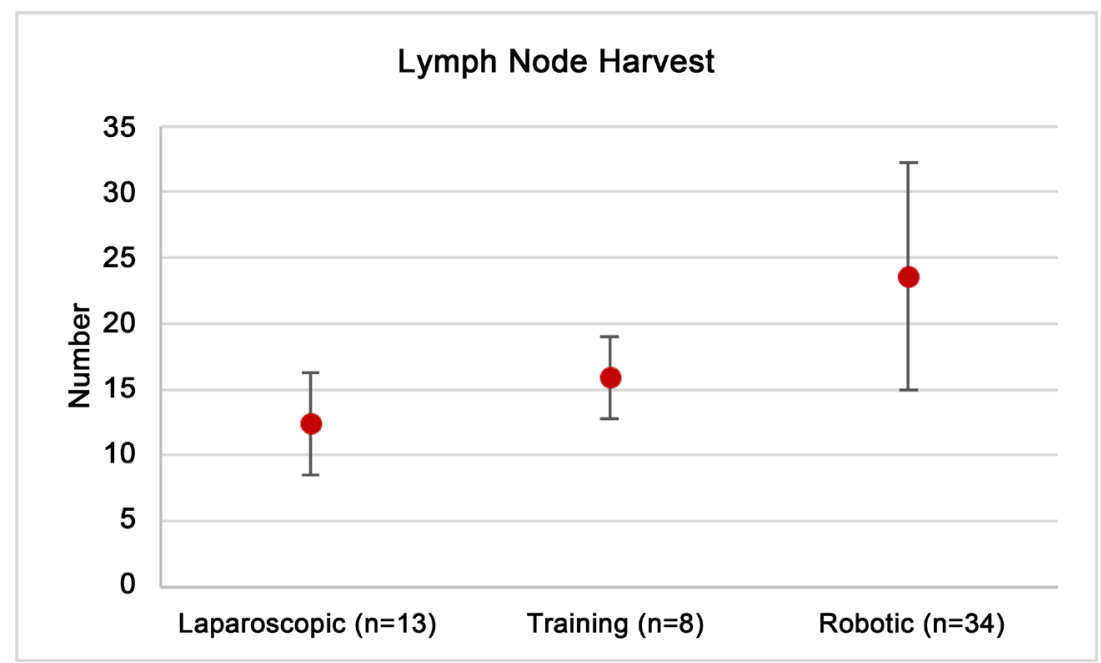

Figure 2. Technical Ability: Lymph Node Harvest.

There were three total instances of reoperation throughout the study. Two were within the Training group, both due to the need for surgical repair of an anastomotic leak. One case in the Robotic group required reoperation due to prolonged ileus and subsequent small bowel obstruction.

There was one case of perioperative mortality in the Robotic cohort. The patient died during coronary catheterization after experiencing a cardiovascular complication.

Technical Ability in oncologic resection is given in Table 4 and Figure 2. Harvest of lymph nodes was quantitatively analyzed in applicable cases. There were a significantly higher number of lymph nodes harvested in oncologic cases within the Robotic group when compared with the Laparoscopic group $(\mathrm{p}<0.05)$.

\section{Discussion}

The data as collected in this study suggest that the robotic partial colon resection shows significant differences in comparison to the laparoscopic approach, most notably through the difference found in the number of operations that were converted to open and reduced blood loss. Conversion to open negates the noted benefits of minimally invasive surgery. We hypothesize that the greatly significant reduction in conversion rate in the robotic group may be due to many factors including the technical capability arising from fully articulating instrumentation, clearer visualization, and adaptability with the robotic system when 
compared to similar laparoscopic procedures. The precision of robotic-assisted surgery makes it a reasonable alternative in difficult surgical situations where the laparoscopic approach may not be adequate [3]. An additional and significant impact of the greater technical capability of the robotic system is the elimination of a selective approach to offering MIS. Prior to adopting robotics in this practice, the use of a laparoscopic method averaged $58.3 \%$ of electively scheduled partial colectomy cases. After adoption, the application of robotics to partial colectomy approaches $100 \%$ of elective case volume.

The robotic approach may also confer benefits to postoperative patient recovery. Decreased hospital stay may indicate a more robust patient recovery postop. The exact cause of decreased length of stay is not entirely clear. We postulate that, although some parts of the impact are accounted for by improved surgical technique, some of the effects are results of increased use of various elements of enhanced recovery pathways [12]. There were no significant differences in morbidity or mortality between laparoscopic and robotic groups. However, we suspect that this may be in part due to the limited amount of data.

In scrutiny of operation time, robotic cases were significantly longer. We suspect this is likely a reflection the wider spectrum of more difficult partial colectomies not attempted laparoscopically prior to adoption of robotics. The longer operation time may also be in part due to the docking and undocking of the robot itself, a maneuver which is not necessary in laparoscopic cases [3] [13]. The efficiency of the docking process is highly dependent on the familiarity of the surgical team with the da Vinci Robotics system and can therefore be quite variable. This may also be affected by the generation of robot used, and is a possible parameter to evaluate in future study. Two generations of the da Vinci Robot, $S i$ and $X i$, were used in accordance with what was available at the medical facility of interest over the course of the material analyzed. Therefore, technical advances between the first and second iteration of the robot used in this study were not evaluated. Although docking time may not completely remove the significant difference in operation time, the decrease in hospital stay may outweigh the longer time spent operatively. Overall, the demonstrated advantages in patient outcomes could outweigh long setup and procedure time [3] [13]. Evaluation of the two variables in comparison to one another is outside of the scope of this study and a point for future research.

Although this study is unique in its ability to control for many independent variables due to the consistency in the medical staff and resources available, it should be mentioned that there may be limits to this research since it is an evaluation of only one physician's work. Our data was highly dependent on one surgeon's skill and individual experience [14]. Additionally, advances in medical treatment that were implemented within this time span of this project which may influence the data could not be accounted for [12].

The cost of the robotic approach in comparison to that of laparoscopic and open procedures has been a topic of interest since its debut as a surgical tool [1] 
[8]. Collecting information about overall cost was beyond the scope of this study. However, we hypothesize that the gap between laparoscopic and robotic surgical costs may not be as wide as was previously thought [1] [15]. The lifetime use of robotic equipment greatly dilutes its initial cost. More importantly, the advantages that robotic surgery may confer in patient healing as shown by decreased hospital stay may prove to be a major factor in reducing overall hospital cost of surgical patient care [1] [8] [15].

Although data was collected as concisely as possible, changes in record-keeping practices over time this institution may have played an immeasurable influence on data that was collected.

Many studies have shown the comparable safety and results of laparoscopic and robotic approaches to colon resection [7] [9] [11] [16]. However, robotics is an innovative way to reestablish some advantages of open surgery that were lost in the transition to laparoscopy, including 3D visualization, free motion of surgical instruments, and stabilization [4] [9]. Robotics also confers a serious advantage when considering large surgical volumes due to the increased availability of the minimally invasive approach to patients that would not be ideal candidates for a purely laparoscopic approach [3] [6] [7] [17] [18]. Although operating times are substantially longer, our evaluation of evidence at this institution demonstrates that the benefits of robotic-assisted surgery are substantial in several aspects of the surgical approach, specifically intraoperative technical ability and patient outcomes as indicated by shortened hospital stay.

\section{Disclosures}

Dr. Francis Buzad serves as a proctor for Intuitive Surgical, Inc. (Sunnyvale, CA).

\section{References}

[1] Hollis, R.H., Cannon, J.A., Singletary, B.A., Korb, M.L., Hawn, M.T. and Heslin, M.J. (2016) Understanding the Value of Both Laparoscopic and Robotic Approaches Compared to the Open Approach in Colorectal Surgery. Journal of Laparoendoscopic \& Advanced Surgical Techniques A, 26, 11.

https://doi.org/10.1089/lap.2015.0620

[2] Lacy, A.M., García-Valdecasas, J.C., Delgado, S., Castells, A., Taurá, P., Piqué, J.M. and Visa, J. (2002) Laparoscopy-Assisted Colectomy versus Open Colectomy for Treatment of Non-Metastatic Colon Cancer: A Randomized Trial. Lancet, 3599, 2224-2229. https://doi.org/10.1016/S0140-6736(02)09290-5

[3] Massimilliano, F., Cirillo, P. and Corcione, F. (2016) Surgical Approach to Right Colon Cancer: From Open Technique to Robot. State of the Art. World Journal of Gastrointestinal Surgery, 8, 564-573. https://doi.org/10.4240/wjgs.v8.i8.564

[4] Benlice, C., Aytac, E., Costedio, M., Kessler, H., Abbas, M.A., Remzi, F.H. and Gorgun E. (2016) Robotic, Laparoscopic, and Open Colectomy: A Case-Matched Comparison from the ACS-NSQIP. The International Journal of Medical Robotics and Computer Assisted Surgery, 1-6.

[5] Luca, F., Ghezzi, T.L., Valvo, M., Cenciarelli, S., Pozzi, S., Radice, D., Crosta, C. and 
Biffi, R. (2011) Surgical and Pathological Outcomes after Right Hemicolectomy: Case-Matched Study Comparing Robotic and Open Surgery. The International Journal of Medical Robotics and Computer Assisted Surgery, 7, 298-303. https://doi.org/10.1002/rcs.398

[6] Tonutti, M., Elson, D.S., Yang, G.Z., Darzi, A.A.W. and Sodergren, M.H. (2017) The Role of Technology in Minimally Invasive Surgery: State of the Art, Recent Developments and Future Directions. Postgraduate Medical Journal, 93, 159-167. https://doi.org/10.1136/postgradmedj-2016-134311

[7] D’Annibale, A., Morpurgo, E., Fiscon, V., Trevisan, P., Sovernigo, G., Orsini, C. and Guidolin, D. (2004) Robotic and Laparoscopic Surgery for Treatment of Colorectal Diseases. Diseases of the Colon \& Rectum, 47, 2162-2168. https://doi.org/10.1007/s10350-004-0711-Z

[8] Rodriguez-Sanjuan, J.C., Gomez-Ruiz, M., Trugeda-Carrera, S., Manuel-Palazuelos, C., Lopez-Useros, A. and Gomez-Flietas, M. (2016) Laparoscopic and Robot-Assisted Laparoscopic Digestive Surgery: Present and Future Directions. World Journal of Gastroenterology, 22, 1975-2004. https://doi.org/10.3748/wjg.v22.i6.1975

[9] Park, J.S., Choi, G.S., Lim, K.H., Jang, Y.S. and Jun, S.H. (2010) Robotic-Assisted versus Laparoscopic Surgery for Low Rectal Cancer: Case-Matched Analysis of Short-Term Outcomes. Annals of Surgical Oncology, 17, 3195-3202. https://doi.org/10.1245/s10434-010-1162-5

[10] Torricelli, F.C., Barbosa, J.A. and Giovanni, S.M. (2016) Impact of Laparoscopic Surgery Training Laboratory on Surgeon's Performance. World Journal of Gastrointestinal Surgery, 8, 735-743. https://doi.org/10.4240/wjgs.v8.i11.735

[11] Pigazzi, A., Ellenhorn, J.D., Ballantyne, G.H. and Paz, I.B. (2006) Robotic-Assisted Laparoscopic Low Anterior Resection with Total Mesorectal Excision for Rectal Cancer. Surgical Endoscopy, 20, 1521-1525. https://doi.org/10.1007/s00464-005-0855-5

[12] Shida, D., Tagawa, K., Inada, K., Nasu, K., Seyama, Y., Maeshiro, T., Miyamoto, T., Inoue, S. and Umekita, N. (2017) Modified Enhanced Recovery after Surgery (ERAS) Protocols for Patients with Obstructive Colorectal Cancer. BMC Surgery, $17,18$.

[13] Jensen, J.S., Antonesen, H.K. and Durup, J. (2017) Two Years of Experience with Robot-Assisted Anti-Reflux Surgery: A Retrospective Cohort Study. International Journal of Surgery, 39, 260-266. https://doi.org/10.1016/j.ijsu.2017.02.014

[14] Lujan, H.J., Maciel, V.H., Romero, R. and Plasencia, G. (2013) Laparoscopic Versus Robotic Right Colectomy: A Single Surgeon's Experience. Journal of Robotic Surgery, 7, 95-102. https://doi.org/10.1007/s11701-011-0320-5

[15] Hagen, M.E., Rohner, P., Jung, M.K., Amirghasemi, N., Buchs, N.C., Fakhro, J., Buehler, L. and Morel, P. (2017) Robotic Gastric Bypass Surgery in the Swiss Health Care System: Analysis of Hospital Costs and Reimbursement. Obesity Surgery, 27, 2099-2105. https://doi.org/10.1007/s11695-017-2613-x

[16] Hellan, M., Anderson, C., Ellenhorn, J.D., Paz, B. and Pigazzi, A. (2007) Short-Term Outcomes after Robotic Assisted Total Mesorectal Excision for Rectal Cancer. Annals of Surgical Oncology, 14, 3168-3173. https://doi.org/10.1245/s10434-007-9544-z

[17] Moser, F. and Horgan, S. (2004) Robotically Assisted Bariatric Surgery. The American Journal of Surgery, 188, 38S-44S. https://doi.org/10.1016/j.amjsurg.2004.08.027

[18] Oldani, A., Bellora, P., Monni, M., Amato, B. and Gentilli, S. (2017) Colorectal Surgery in Elderly Patients: Our Experience with DaVinci System. Aging Clinical and Experimental Research, 29, 91-99. https://doi.org/10.1007/s40520-016-0670-y 
Submit or recommend next manuscript to SCIRP and we will provide best service for you:

Accepting pre-submission inquiries through Email, Facebook, LinkedIn, Twitter, etc. A wide selection of journals (inclusive of 9 subjects, more than 200 journals)

Providing 24-hour high-quality service

User-friendly online submission system

Fair and swift peer-review system

Efficient typesetting and proofreading procedure

Display of the result of downloads and visits, as well as the number of cited articles Maximum dissemination of your research work

Submit your manuscript at: http://papersubmission.scirp.org/

Or contact ss@scirp.org 